\title{
POLÍTICAS PÚBLICAS E SOCIEDADE
}

\author{
Roberta Morais da Silva ${ }^{1}$ \\ Diógenes José Gusmão Coutinho²
}

RESUMO: Esse estudo é referente às políticas públicas e a sua implementação para a sociedade, sejam elas políticas econômicas, sociais, financeiras etc. O modelo a seguir busca estabelecer uma correspondência entre o momento da implementação da política até sua concretização. São analisados diversos conceitos básicos de políticas públicas e seus impactos na sociedade, destacando sua importância para a realização da democracia no Brasil. Seu objetivo principal é investigar a importância da promoção de políticas públicas e seus benefícios para que possamos ter uma sociedade mais igualitária no que diz respeito a direitos sociais, de acordo com o artigo $3^{\mathrm{o}} \mathrm{da}$ constituição federal de 1988. É necessário que ações sejam planejadas e executadas com o objetivo de solucionar uma situação que seja vista como um problema para a população. A gestão pública moderna traz um questionamento no que diz respeito aos paradigmas do Direito Administrativo, com o intuito de que as ações sejam descentralizadas. Foi desenvolvido um estudo do tipo pesquisa bibliográfica, onde o material estudado foi baseado em escritos de outros pesquisadores. Mostra-se no presente trabalho que a promoção de políticas públicas reflete numa melhor qualidade de vida para os seres, partindo do pressuposto de que é função do Estado promover o bem-estar da sociedade.

Palavras-chave: Políticas públicas. Nova gestão pública. Direitos sociais.

\footnotetext{
' Servidora técnica-administrativa da Universidade Estadual da Paraíba. Graduação em Bacharelado em Administração Pública pela Universidade Estadual da Paraíba (2014) e bacharelado em Ciências Contábeis pela Faculdade Cruzeiro do Sul (2020). Especialista em MBA em Administração Pública e Gerência de Cidades (2016) e em Pesquisa Avançada em Educação (2019). E-mail: robertauepb@gmail.com.

2 Doutor em Biologia Vegetal da UFPE. Atualmente Leciona disciplinas da área de Saúde no ensino técnico, tecnológico, graduação e pós-graduação. Disciplinas a qual está apto a lecionar: Gestão em saúde, epidemiologia, anatomia, genética, parasitologia, biossegurança, micologia médica, química ambiental, ecologia, botânica. Tem experiência em pesquisa na área de Fitoquímica, atuando especificamente na área de química aplicada, biocombustíveis, quimiotaxonomia, plantas nativas potencialmente alimentícias, ecologia e bioquímica vegetal. É Membro do Laboratório de Ecologia Aplicada e Fitoquímica agregado ao Departamento de Botânica do Centro de Ciências Biológicas (CCB) da UFPE. E-mail: gusmao.diogenes@gmail.com.
} 
ABSTRACT: This study refers to public policies and their implementation for society, whether they are economic, social, financial and etc. The following model seeks to establish a correspondence between the moment of policy implementation and its implementation. Several basic concepts of public policies and their impacts on society are analyzed, highlighting their importance for the realization of democracy in Brazil. Its main objective is to investigate the importance of promoting public policies and their benefits so that we can have a more egalitarian society with regard to social rights, according to Article 3 of the 1988 Federal Constitution. It is necessary that actions are planned and carried out with the objective of solving a situation that is seen as a problem for the population. Modern public management raises a question regarding the paradigms of Administrative Law, with the intention that actions are decentralized. A study of the bibliographic research type was developed, where the material studied was based on the writings of other researchers. It is shown in this work that the promotion of public policies reflects a better quality of life for beings, based on the assumption that it is the role of the State to promote the well-being of society.

Keywords: Public policies. New public management. Social rights.

\section{INTRODUÇÃO}

Este artigo possui a finalidade de esclarecer sobre o tema Políticas Públicas e Sociedade, visto que a população precisa de uma experiência prática e um acompanhamento de onde se aplica grande parte dos investimentos com o dinheiro público e também em que isso reflete na qualidade de vida da nação, através de políticas públicas voltadas para a sociedade.

Os avanços alcançados pelas políticas públicas voltadas à redução das desigualdades e, de forma mais ampla, pelo sistema de promoção e proteção social brasileiro têm sido objeto de diversos estudos focados em compreender os processos de consolidação da política social no país e suas repercussões sobre as políticas de educação, saúde e assistência social na esteira das mudanças institucionais que acompanharam os novos paradigmas previstos pela Constituição Federal de 1988 CF/1988 (Arretche, 2018; Menicucci e Gomes, 2018).

Com o término da segunda guerra mundial os países tidos como subdesenvolvidos traçaram como principal objetivo o crescimento com $o$ desenvolvimento, sendo assim posto em pauta nos debates internacionais. A busca por novas formas de governo que oferecessem mais eficiência de maneira menos burocrática se deu com a crise do Estado social. Após a constituição de 1988 ser 
promulgada foram observadas mudanças relevantes nas atitudes de governos, que conseguiu intensificar-se em meados da década de noventa.

No Brasil atual, onde os destinos do País sejam levados em conta, problemas como dificuldade financeira, desigualdade de vida, questão social, é importante que as conquistas sociais existam, para assim se ter um País com uma sociedade vivendo em condições de vida mais dignas.

Entende-se por desigualdade social um conjunto de elementos, sejam políticos, econômicos, próprios de uma sociedade. Essa desigualdade social assola a sociedade Brasileira, são problemas de desemprego, concentração de renda, violência etc.

A grande desigualdade social enfrentada atualmente cria a necessidade da sociedade buscar cada vez mais seus direitos, estabelecidos por legislação específica, na busca de um mundo mais justo para todos.

É fato que o brasileiro vive em um meio onde as diferenças sociais são elevadas, contanto, é essencial que seja exercida a cidadania, onde todo cidadão tenha direito a igualdade e justiça social. A garantia desses direitos traz uma forma de viver democraticamente, porém, os direitos humanos estão previstos em lei, devem ser postos em prática.

Dentro deste novo contexto, surgem os novos moldes voltados para a materialização de conquistas sociais, que serão assegurados através de políticas públicas.

As políticas públicas trazem em suas etapas, seja na elaboração, implantação e em seus resultados, interpretações de poder político, onde se envolvem vários projetos e interesses, contrários ou não, mas com um mínimo de consenso, para que só assim, venham a ser legitimadas e obterem resultados positivos. São questionamentos necessários na elaboração de uma política pública: quem decide o quê? Quando? Com quais conseqüências? Para quem? São questionamentos baseados nas demandas da sociedade, relacionadas com o sistema político em que são submetidas. Diante dessa realidade, faz-se necessário considerar que os resultados e benefícios, sejam voltados para um bem comum.

As políticas públicas ajudam para que uma população chegue ao desenvolvimento. Para isso, precisa-se de um acompanhamento, um sistema de 
avaliação, através de uma elaboração de um programa com a realidade dessa população, após identificada essa etapa, vem a fase de implementação da política, onde são feitas as revisões do projeto inicial e escolha de estratégias para uma maior eficiência dos programas, baseando se no retorno dos resultados obtidos para que assim seja feita uma possível reformulação. Por final, é feita uma avaliação, se esse tipo de política implantado atingiu um resultado esperado.

Política Pública é um avanço em prol da população e que vem para garantir direitos das pessoas, surge de compromisso público entre determinada sociedade e o órgão gestor. As políticas públicas são criadas através da elaboração de um plano de ação.

Temas de interesse coletivo como a promoção de melhorias no bem estar social, devem receber uma maior importância por parte da esfera pública, sendo fundamental a participação da sociedade, nas etapas de avaliação de políticas públicas, para que essas ajam diretamente no intuito de solucionar as dificuldades da comunidade. As políticas Públicas são importantes, pois trazem soluções que contribuem com a concretização das demandas da sociedade.

Ampliar as ações públicas e incentivar investimentos nessa área demonstra a boa vontade dos órgãos públicos em atenderem os anseios da população. A participação da sociedade nas discussões de enfrentamento das dificuldades e na resolução dos problemas servirá para surgirem novas visões. A comunicação entre poderes públicos e sociedade possibilita o aumento do conhecimento e transforma a vida dessa sociedade.

Entende-se por Políticas Públicas um conjunto de programas, desenvolvidos pelos Órgãos Públicos, de forma direta ou indiretamente, com o apoio de entes públicos ou privados, visando garantir o direito à cidadania comum.

Podemos entender por sociedade como um grupo de pessoas que convivem no mesmo espaço, com interesses em comum e que são geridos por órgãos que devem zelar pelo interesse coletivo, estando assim sujeitos as mesmas leis.

Ser cidadão é cumprir com suas obrigações e ter a garantia de seus direitos civis, políticos e sociais, para uma sociedade, ter esses direitos respeitados e cumpridos é ter a garantia de viver em um meio mais justo e democrático. 
Políticas públicas estão diretamente relacionadas com o desenvolvimento e a promoção de melhorias comuns para a sociedade.

No entanto, o problema desse artigo consiste em esclarecer: Qual a importância da promoção de políticas públicas para a sociedade? Nesse contexto, o presente trabalho busca analisar e fazer um controle sobre o surgimento dos programas que implementaram as políticas públicas no Brasil. Partindo de uma breve reflexão sobre política pública e participação da sociedade, discutem-se as etapas de criação de políticas públicas e seu reflexo positivo na qualidade de vida da sociedade.

Para tanto, o estudo foi estruturado em três partes, que permitiu situar a fundamentação teórica para subsidiar o mesmo e de maneira metodológica expor os resultados obtidos.

$\mathrm{Na}$ primeira parte, do trabalho é efetuado o enquadramento conceitual, onde se procede a revisão científica existente sobre o tema desta investigação. $\mathrm{Na}$ segunda parte do trabalho, está apresentado o desenvolvimento metodológico do estudo, abordando os materiais e métodos utilizados, descrevendo-se o tipo de investigação, as variáveis do estudo e, maneira como foi aplicado o instrumento. Para finalizar, tem se a explanação e análise dos dados referentes ao presente estudo.

\section{OBJETIVO GERAL}

- Transcorrer sobre o reflexo da promoção de políticas públicas para a sociedade.

\section{OBJETIVOS ESPECÍFICOS}

- Expor a perspicácia de pessoas no que diz respeito ao acesso da população a políticas públicas.

- Apresentar de forma resumida características dos modelos analisados.

- Apresentar resultado da importância da promoção de políticas públicas.

- Identificar elementos que contribuam para a implantação de políticas públicas.

\section{FUNDAMENTAÇÃO TEÓRICA}

Para Secchi (2015, p. 2), política pública é tida como uma diretriz elaborada para enfrentar um problema público. Isto é, pode assumir as mais diversas formas 
concretas, sendo decidida nas mais diferentes instâncias da sociedade, públicas ou privadas (WU et al., 2014)

Diante do exposto acima, tem-se como de grande importância, no momento de avaliação por parte do Estado, de políticas públicas a serem implantadas, o respeito as prioridades e necessidades da população, visto que é assegurado na Constituição Federal, o direito a políticas públicas com o intuito de crescimento e desenvolvimento da população

O Brasil é um país onde a política existe há anos, porém de acordo com o ranking mundial, o país configura-se como um dos maiores promovedores da desigualdade social. A pobreza, a falta de moradia, as péssimas condições da saúde pública, são essenciais para que o povo Brasileiro não consiga ter sua cidadania respeitada. Com isso, surgem idéias como soluções para esses problemas, o que na maioria das vezes essas idéias são substituídas pelo que de fato deveria ser a amenização dessas dificuldades: a implantação de políticas públicas. Políticas essas garantidas pela Constituição Federal, que venham para mudarem a realidade que vivem as famílias carentes do País, políticas que ofereçam ações ligadas a saúde, educação, habitação, e outras medidas em comum que facilitem a vida dos que mais precisam.

Ultimamente, a administração pública vem se superando em resultados como redução de cortes no orçamento, eficiência na prestação de serviços com redução de gastos. Nesse contexto, entende-se que o setor público está mais perto dos seus fornecedores/clientes, na medida que aproxima os serviços da população. Deve-se buscar meios onde ocorra a descentralização nas atividades administrativas.

Partindo desse pressuposto, o Administrador público deve enxergar que o orçamento público é a ferramenta fundamental para a gestão pública. Levando em consideração que a administração pública deve atender aos interesses para o bem comum da população, a utilização dos recursos públicos deve ser obrigatoriamente aprovada pelos órgãos competentes e publicados em forma de lei, atendendo aos interesses da sociedade.

Deve-se observar que a Administração Pública passa por um processo de evolução, no qual se exige de todo gestor público que suas ações sejam bem planejadas 
e transparentes, com o intuito de equilibrarem as contas públicas. Uma das formas de ação de Governo mais efetiva é a promoção de políticas públicas, voltadas para o interesse e o bem da sociedade.

Essas políticas são de cunho administrativo, econômico, social etc. As políticas sociais são aquelas voltadas às garantias fundamentais e envolvem os serviços de assistência social, educação, saúde, previdência etc.

Nas últimas décadas, problemas enfrentados pela população tais como: desemprego, exclusão e desigualdade social, alterações na estrutura familiar, dentre outros, inspiraram a precisão de introdução de políticas públicas, com o objetivo de uma melhor humanização na qualidade de vida das pessoas.

É de suma importância que os órgãos públicos resolvam as demandas advindas da sociedade, para que possa ocorrer um contentamento com a política empregada. $O$ Estado se apresenta como uma unidade básica social com território definido e com uma nação constituída pela coletividade que habita determinada localidade, genericamente entendida como um povo. Atualmente, a principal forma de organização política dáse por meio do Estado Moderno.

A sociedade civil, legitimadora e financiadora do Estado, o credencia a administrar as questões mais importantes do convívio social e, em nome da ordem, concede também a ele o direito de ser a única instituição a poder fazer o uso legítimo da força física conforme destacou Max Weber (ALBINO, 20I6).

A sociedade tem um grande aliado ao buscar solução para os problemas que afetam o bem-estar social, as políticas públicas, elas que, através de leis, orientam os gestores e a população para qual a melhor maneira onde os recursos públicos devem ser aplicados com retorno em ações para uma sociedade em geral. $\mathrm{O}$ resultado dessas políticas tem um saldo positivo e são vistas pelos governantes como a verdadeira resolução de problemas.

Ultimamente, a sociedade tornou-se mais exigente, no sentido de não avaliar apenas os resultados obtidos com a implementação de políticas públicas, mais também como são feitos os investimentos e como o dinheiro público está sendo aplicado.Com isso, torna-se necessário que a população seja conhecedora dos problemas da 
comunidade e que exija ações no intuito de promoverem verdadeiras mudanças nos considerados vexames para a população.

É importante que a população perceba que o interesse dos gestores em melhorarem as condições de vida de uma sociedade, vai a partir do interesse da mesma.

A Lei Complementar n.ํ 13I (Lei da Transparência), de 27 de maio de 2009, quanto à participação da sociedade, assim determina:

- Deve-se haver audiências públicas com a participação em massa da população para que sejam elaborados e discutidos planos para destinação do orçamento.

- Deve haver publicidade por meio de acesso público com relação a execução orçamentária e financeira dos recursos.

Após essa obrigação através de lei de que todas as esferas devem permitir que a população participe da administração, o cumprimento da mesma faz-se direito da população e obrigação do Estado.

Após a sociedade identificar as demandas sociais, inicia-se o processo de formulação/seleção das alternativas possíveis, momento em que são aclaradas as posições políticas e ideológicas dos atores em conflito e em que o Estado irá procurar demonstrar a viabilidade das propostas e depois buscar a concretização de uma política pública específica para resolver essas demandas da sociedade. Tomadas às decisões, dáse a fase da implementação da política pública por parte dos representantes públicos.

$\mathrm{Na}$ fase da implementação o que foi formulado tornará realidade, de forma sintética, elas buscam compreender as diferenças entre o que foi formulado e o que foi executado e o papel que os diferentes agentes tiveram nesse processo de transformação das políticas públicas (HILL; VARONE, 20I6).

O ciclo das políticas públicas assim como suas etapas correspondem a uma seqüência, descrita abaixo: elaboração e formulação do problema, incluindo os principais envolvidos, com o objetivo de se alcançar o desenvolvimento; essa formulação do problema a ser solucionado torna-se simples, já que qualquer assunto que esteja relacionado a vida das pessoas pode ser tratado como um problema a ser solucionado.

Identificar através de situações semelhantes e já superadas, linhas de ação para a promoção de políticas públicas, com seus custos e resultados, mostrando a criação de 
novas alternativas; essas ações geralmente são previstas através de uma agenda; um acordo para que se chegue a um consenso de interesse dos envolvidos com a formulação de alternativas sobre as questões mais abordadas pelos envolvidos; é também a fase de planejamento das ações que constam na agenda; tomar uma decisão em torno de soluções práticas, levando em conta a disponibilidade de recursos disponíveis e das estratégias de implementação; é a fase de enfrentamento do problema; na avaliação acompanhar o processo e seus resultados, avaliando sua eficiência.

O Brasil por ser classificado como um país democrático, é importante a concretização de políticas públicas voltadas para o bem comum, com direito a benefícios sociais, como política gerativa de emprego, educação igualitária, saúde com toda infra-estrutura adequada e com servidores capacitados para atenderem as demandas da população, saneamento básico etc.

Portanto, se faz relevante esclarecer que a definição de política pública não implica em atender a interesses de determinados grupos, mas sim, em o Estado encontrar uma maneira de agir que venha a solucionar os conflitos. Diante dessa premissa, o Estado através de políticas públicas deve buscar administrar diferenças entre classes sociais com o objetivo de encontrar equilíbrio de demandas.

Metodologia

As técnicas de pesquisa servem como ferramentas na produção de uma investigação. A escolha das técnicas está ligada diretamente com o objeto de estudo que foi construído. Essas técnicas de pesquisa devem ser consideradas adequadas pelos membros de uma comunidade. Algumas comunidades científicas se organizam em torno da adoção de um conjunto limitado de técnicas de pesquisa.

O estudo bibliográfico, pelo qual foi desenvolvido esse artigo, tomou como base a bibliografia já existente em forma de revistas, publicações escritas, livros dentre outros. Foi explorado um vasto conteúdo sobre o assunto aqui abordado, onde permitiu um maior conhecimento do tema por parte do cientista, que pôde fazer uma reflexão na história da relação entre sociedade e Estado, no que se referia a políticas públicas.

Nesta etapa, descreve-se qual a metodologia utilizada para a concretização deste estudo, cujo objeto é importância da promoção de políticas públicas para a sociedade. 
Trata-se de um objeto complexo, pois envolve uma relação dinâmica entre vários atores.

A referida pesquisa de campo foi desenvolvida levando-se em consideração os seguintes aspectos: Tipo de investigação, amostra de estudo, instrumento de coleta de dados, análise e discussão dos dados. Na pesquisa bibliográfica, a coleta e análise dos dados analisa e descreve o fenômeno em sua forma complexa.

Análise e discussão dos dados

A presente etapa do trabalho visa mencionar, organizar e detalhar o que foi conseguido no transcorrer da pesquisa. A metodologia na pesquisa bibliográfica implica em um estudo teórico e complexo da produção científica, que é realizada em torno de um determinado assunto.

Olhando por esse lado, fala-se de uma metodologia capaz de solucionar um problema, a pesquisa bibliográfica define bem suas técnicas e critérios de coleta de dados.

A maneira escolhida para apresentação dos dados coletados foi através de um texto narrativo. $\mathrm{O}$ artigo em uma pesquisa bibliográfica, ou seja, as informações colhidas foram obtidas através de fontes secundárias, documentos (fontes vindas de bases de dados online, de livros, revistas especificassem determinado tema, trabalhos acadêmicos, sítio da web e outros).

$\mathrm{Na}$ escolha da análise qualitativa não usa o fator teórico de maneira formal, ao contrário, essa revisão é feita dentro de todas as etapas do processo de investigação, com ênfase para a parte da discussão dos dados, que engloba a descrição e interpretação desses dados. A interpretação é a análise com relação e comparação de diferentes opiniões sobre o assunto. Como resultados de um estudo bibliográfico, faz-se necessário uma abordagem da política pública, vista como solução para a sociedade, no enfrentamento de dificuldades.

Diante disso, percebe-se, que investigar as políticas públicas não é só um desafio, mas exige uma análise das opiniões expostas nos programas. Torna-se essencial o avanço na implementação de políticas públicas, colocando em prática a transformação da sociedade. Diante do exposto, esclarece-se que o poder público tem 
a obrigação de transformar a sociedade, onde garanta os direitos assegurados na Constituição de 1988.

Política pública é um assunto onde os desafios são grandes, portanto é de suma importância aprofundar o diálogo e ampliar a discussão, pois, a busca de soluções torna-se viável.

\section{CONCLUSÃO}

O artigo intitulado Políticas Públicas e Sociedade, favorece uma qualificação técnica, e, principalmente, social, onde se tem um maior esclarecimento sobre a importância das políticas públicas para a sociedade.

Um certo conhecimento das necessidades de uma população causa o descobrimento de problemas públicos, no qual fica responsável o Estado de elaborar soluções para essas demandas e concretizar com a implementação de políticas públicas voltadas para programas que atendam essas dificuldades e de uma certa forma, promover uma maior humanização no trato com as dificuldades encontradas pela sociedade em geral.

O planejamento, acompanhamento e monitoramento de políticas públicas evitam que políticas com pouco resultado sejam colocadas em práticas, um certo estudo para a promoção de políticas públicas é necessário para que os resultados para a sociedade sejam os maiores e melhores.

Como sugestão para aprofundamento futuro do referente estudo, é pesquisar como aumentar e garantir essa implementação de políticas públicas para um maior número de cidadãos.

A sociedade é responsável por exigir eficiência no desenvolver de políticas públicas. Além da clareza na fase de formulação e implementação dessas políticas, a flexibilidade no tocante aos recursos que estão sendo utilizados permite uma adequação mais racional aos fins visados.

Quanto à opinião de autores, foram aqui expostas sobre o conceito de políticas públicas e suas fases, desde o início até a sua concretização. Também foi levado em conta o que dizem os autores sobre a importância da promoção dessas políticas no combate às desigualdades sociais. 
Enfim, no presente trabalho, foram expostas algumas reflexões, iniciando com a afirmação de que cada etapa aqui realizada trouxe contribuições para melhor identificar a necessidade e importância das políticas públicas no crescimento da sociedade. O conhecimento adquirido através dessa leitura faz perceber que há curiosidades ainda a serem estudadas e esclarecidas.

Com o presente estudo, conclui-se que é papel das políticas públicas combaterem as desigualdades sociais melhorando assim o convívio em sociedade, seja através de direitos sociais ou por políticas econômicas.

\section{REFERÊNCIAS}

ALBINO, Luciano. ıo lições sobre Max Weber. Petrópolis, RJ: Vozes, 2016. (Coleção Io Lições).

ARRETCHE, M. T. S. Trinta anos da Constituição de I988: razões para comemorar? Novos Estudos - Cebrap, São Paulo, v. 37, n. 3, p. 395-4I4, 2018.

BERCOVICI, Gilberto. Constituição econômica e desenvolvimento. Uma leitura a partir da Constituição de 1988. São Paulo: Malheiros, 2005.

BONAVIDES, Paulo. Do Estado liberal ao estado social. $7^{\underline{a}}$ ed., $2^{\underline{a}}$ tiragem. São Paulo: Malheiros, 2004.

GIL, A. C. Como elaborar projetos de pesquisa. São Paulo: Atlas, 2008.

HILL, M. J.; VARONE, F. The public policy process. 7th ed. London: Routledge, 2016.

LINDBLOM, C. Todavia tratando de salir del paso. SARAVIA, E; FERRAREZI, E.(orgs.) Políticas públicas: coletânea. Brasília: ENAP, 2006, p.99-ı22.

MARCONI, M. A.; LAKATOS, E. M. Fundamentos de metodologia científica. São Paulo: Atlas, 2007. 
MENICUCCI, T.; GOMES, S. Políticas sociais: conceitos, trajetórias e a experiência brasileira. Rio de Janeiro: Fiocruz, 2018.

OHLWEILER, Leonel. A construção e implementação de políticas públicas: desafios do Direito administrativo moderno. Verba Juris ano 6, n. 6, jan./dez. 2007.

Disponível em: \&lt; periodicos.ufpb.br/ojs/index.php/vj/article/download/I4868/8423\&gt;.

Acesso em: 12/10/2015

SANTOS, Maria Paula Gomes dos. Políticas públicas e sociedade. Florianópolis: Departamento de Ciências da Administração / UFSC, 2012. ıoop.

SCHNEIDER, Volker. Redes de políticas públicas e a condução de sociedades complexas. Civitas - Revista de Ciências Sociais, v. 5. n. I, p. 29-57, jan.-jun. 2005.

SECCHI, L. Políticas Públicas: conceitos, esquemas de análise, casos práticos. 2 ed. São Paulo: Cengage Learning, 2015.

SOUZA, Celina. Políticas Públicas: uma revisão da literatura. IN Sociologias nº I6. Junho/dezembro 2006, p. 20-45.

VERZA, Severino Batista. As Políticas Públicas de Educação no Município. Ijuí ed. UNIJUÍ, 2000, p. 84-87. 